\title{
ADSORPTION CAPACITY OF GAC PILOT FILTER-ADSORBER AND POSTFILTER- ADSORBER FOR INDIVIDUAL THMS FROM DRINKING WATER, ATHENS
}

\author{
K.G. BABI ${ }^{1^{*}}$ \\ K.M. KOUMENIDIS ${ }^{1}$ \\ C.A. MAKRI ${ }^{1}$ \\ A.D. NIKOLAOU ${ }^{2}$ \\ T.D. LEKKAS ${ }^{1}$
}

\author{
${ }^{1}$ Department of Environmental Studies \\ ${ }^{2}$ Department of Marine Sciences \\ University of the Aegean \\ University Hill, 81100 Mytilene, Greece
}

Received: $16 / 03 / 10$

Accepted: 28/06/10 *to whom all correspondence should be addressed: e-mail: kbabi@env.aegean.gr

\section{ABSTRACT}

Trihalomethanes are a major class of chlorination by-products in drinking water. They are formed when chlorine reacts with bromide $\left(\mathrm{Br}^{-}\right)$and natural organic matter (NOM) in source waters. Toxicology studies have shown all THMs to be carcinogenic or to cause adverse reproductive or developmental effects in laboratory animals. THMs are small volatile molecules, which are hydrophobic, non biodegradable and adsorbable on granular activated carbon (GAC).

The objective of this pilot study is to evaluate the adsorption capacity for individual THMs of a GAC filter-adsorber (A) and a GAC postfilter-adsorber (B), both fed with chlorinated natural water.

For this purpose, a GAC pilot plant was operated as a filter-adsorber and a postfilter-adsorber in Galatsi WTP, Athens (GTP) until the removal of individual THMs by GAC was eliminated (breakthrough). Regular sampling was performed during operation and the parameters measured were: THMs, DOC, free residual chlorine, bromide, turbidity, $\mathrm{pH}$ and temperature.

From the experimental data, GAC bed life, GAC usage rate, GAC loading and operation time to breakthrough were calculated for most THMs. TBM was almost not detected. Some desorption of THMs, especially TCM and BDCM, was noticed during the operation of both adsorbers.

Near breakthrough for THMs, equilibrium between adsorbed and dissolved THMs was considered to have been established. The GAC equilibrium loading of individual THMs was assumed to depend on the mean value of their influent concentration, which was not constant. By correlating the equilibrium data by linear regression to conform to the Freundlich isotherm, the Freundlich constants $1 / \mathrm{n}$ and $\mathrm{k}$ were determined for each of THMs. They are related to the physicochemical characteristics and background organics of water and the specific GAC used. The strength of the adsorption bond and the GAC capacity was higher for DBCM, lower for BDCM and even lower for TCM for both adsorbers. In addition, the GAC(B) capacity for BDCM and DBCM was higher than that of GAC(A), probably due to larger surface area and surface chemistry of $\mathrm{GAC}(\mathrm{B})$. Also, the lower particle size and the higher uniformity coefficient of $\mathrm{GAC}(\mathrm{B})$, along with the lower flow rate may have attributed to that by enhancing GAC equilibration. However, TCM was less adsorbed by GAC(B), probably due to the stronger competition effect by BDCM and $\mathrm{DBCM}$, being in much higher mean influent concentration.

The DOC content of influent water seems also to reduce significantly the adsorption of THMs (especially of TCM), as the comparison of our results with the isotherm results with distilleddeionized water by other researchers showed.

KEYWORDS: TCM, BDCM, DBCM, GAC, adsorption, filter-adsorber, postfilter-adsorber.

\section{INTRODUCTION}

Chlorination is the most common disinfection method of drinking water. Although it is important to the supply of safe drinking water, it also leads to the formation of undesirable organic-by-products (Disinfection-by-products, DBPs). A main class of chlorination- by-products is trihalomethanes 
$(\text { THMs })^{1}$ (Arora et al., 1997). They are formed when chlorine reacts with bromide $\left(\mathrm{Br}^{-}\right)$and natural organic matter (NOM) in source waters (Nikolaou et al., 2004; Chowdhury et al., 2008).

Toxicology studies have shown all THMs and other DBPs to be carcinogenic or to cause adverse reproductive or developmental effects in laboratory animals (AWWA, 1990; USEPA, 2001; WHO, 2004; Nieuwenhuijsen, 2005; Richardson, 2005). The above findings have demonstrated the importance of regulating DBPs in drinking water. THMs regulations are presented in Table 1.

Table 1. THMs regulations

(Maximum allowable levels: $\mu \mathrm{g} \mathrm{L}^{-1}$ )

\begin{tabular}{lccccc}
\hline & TCM & BDCM & DBCM & TBM & TTHMs \\
\hline EC (1998) & & & & & 100 \\
\hline USEPA (1998) & & & & & 80 \\
\hline WHO (2004) & 200 & 60 & 100 & 100 & \\
\hline
\end{tabular}

Several treatment alternatives have been proposed for the control of THMs in drinking water, such as the removal of precursor material before it interacts with chlorine (by enhanced coagulation, membrane filtration, GAC adsorption), the removal of THMs after formation (by GAC adsorption, air stripping), moving the point-of-chlorination to the end of the treatment process, the use of alternative oxidants and disinfectants e.t.c.(Clark et al., 1991; 1994; 2001; Singer, 1994).

Granular activated carbon (GAC) has been of a special interest due to its ability to remove a wide range of compounds such as odor and color causing compounds, NOM, THMs and other toxic compounds (Speth and Miltner, 1990;1998; Clark et al.,1991; Xie et al., 2002; Zhou et al., 2002; Babi et al., 2003; 2007). GAC has already been used as the medium in a filter-adsorber or a postfilter-adsorber in many water treatment plants in Europe and in the U.S.A. (Graese et al., 1987; AWWA, 1990; Clark et al.,1991; Black et al., 1996).

\section{BACKGROUND}

The adsorption capacity of GAC varies widely, depending on the quality of the source water and the pretreatment given to it. In carbon adsorption columns treating natural water, many factors can reduce a carbon's adsorption capacity such as: competition for adsorption sites by natural organic matter or other compounds, preloading of organics onto the carbon, development of biofilms, temperature, $\mathrm{pH}$, variable influent concentrations and adsorption kinetics. On-site pilot studies can give a good approximation of full-scale performance of GAC for the removal of NOM and organic DBPs (AWWA, 1990; Black et al., 1996; Graese et al., 1987; Speth and Miltner, 1998).

Isotherm results for THMs in distilled-deionized water and activated carbon (Speth and Miltner, 1990) have showed that the higher the number of bromine atoms THMs molecules contain, the better they are adsorbed on carbon. This has been confirmed by pilot-plant and full-scale plant studies (Clark et al., 1991; AWWA, 1990).

Previous research on the drinking water of Athens, Greece, has showed the occurrence of THMs, HAAs and other DBPs, as well as of NOM in the chlorinated finished drinking water (Golfinopoulos et al., 2003; 2005; Nikolaou et al., 2004).

The removal of total THMs, total HAAs and dissoved organic carbon (DOC) from the drinking water of Athens by GAC treatment has been studied on a pilot-scale (Babi et al., 2003; 2007).

The objective of this pilot study is to evaluate the adsorption capacity of a GAC filter-adsorber and a GAC postfilter-adsorber for individual THMs from Athens drinking water.

\section{MATERIALS AND METHODS}

3.1 Pilot-plant operation:The pilot-plant experiments were conducted in the Water Treatment Plant of Galatsi, Athens (GTP), which is of conventional design. Water treatment applied in the Plant includes prechlorination, coagulation, flocculation, sedimentation, rapid gravity sand filtration and postchlorination.

The pilot-plant consists of a rapid gravity GAC filter.The GAC filter column is constructed of plexiglass and stainless steel to avoid problems of contamination or adsorption of organics from the treated water (APHA, 1992; Babi et al., 2003; 2007).

\footnotetext{
${ }^{1}$ THMs: chloroform (TCM), bromodichloromethane (BDCM), dibromochloromethane (DBCM), bromoform (TBM). The sum of THMs in this work: TTHMs.
} 
In this study the adsorption efficiency of two GAC adsorbers was evaluated:

1) a $\operatorname{GAC}(\mathrm{A})$ (10x20 U.S.mesh) filter-adsorber (loading rate: $7.2 \mathrm{~m} \mathrm{~h}^{-1}$, Empty Bed Contact Time (EBCT): $9.5 \mathrm{~min}$, bed depth: $1.14 \mathrm{~m}, 1$ Bed Volume: $32.3 \mathrm{~L}$, mean duration of filter run: $29.2 \mathrm{~h}$ ) receiving prechlorinated water from the overflow of the sedimentation tanks

2) a GAC(B) (12x40 U.S.mesh) postfilter-adsorber (loading rate: $4.8 \mathrm{~m} \mathrm{~h}^{-1}$, Empty Bed Contact Time (EBCT): $14 \mathrm{~min}$, bed depth: $1.13 \mathrm{~m}, 1$ Bed Volume: $32 \mathrm{~L}$, mean duration of filter run: 6 days) receiving sand-filtered postchlorinated water

The operation of the GAC filters was interrupted by regular backwashing with chlorinated sandfiltered water, when the pressure drop through the filter reached a maximum desirable level. The operation of the GAC filters continued, until the GAC removal efficiency for individual THMs was eliminated (235 for GAC(A) and 638 days for $G A C(B))$. The mass of GAC used was 13.89 and 13.60 $\mathrm{kg}$, respectively. The whole experimental cycles were defined as adsorption cycles for the purpose of this research.

3.2 Sampling and analytical procedure: 10 and 14 sampling events were performed regularly during the operation period of the GAC filter-adsorber and postfilter adsorber, respectively. A little after the start of a filter run, water samples were taken with a peristaltic pump through silicon tubing from the inlet, outlet and different depths in the GAC column. Sample preparation and preservation were performed according to Standard Methods (APHA, 1992).

For the analyses of the samples the following methods were used: THMs: LLE (with MTBE)-GCECD: USEPA method 551.1 (USEPA, 1998a; Nikolaou et al., 2002a); DOC: Persulfate-Ultraviolet oxidation for all the sampling events of the filter-adsorber as well as the first 7 sampling events of the postfilter-adsorber and combustion- infrared method for the last 7 sampling events of the postfilteradsorber, both after sample filtration through $0.45 \mu \mathrm{m}$ syringe filter (APHA, 1992)

The analyses for THMs were performed in the Water and Air Quality Laboratory of the Department of Environmental Studies of the University of the Aegean. The analysis for DOC was performed in Kiourka Laboratory of EYDAP, while the rest of the analyses and measurements were carried out in Galatsi Laboratory of EYDAP.

\section{RESULTS AND DISCUSSION}

\subsection{Experimental results}

From the measurements and analyses performed, the following results the following came out:

The influent values for some parameters, like temperature, $\mathrm{pH}$ and bromide concentration, did not change significantly through the GAC bed. Free residual chlorine in the feed water was about 0.6 $\mathrm{mg} / \mathrm{L}$, while it became zero after the first $20 \mathrm{~cm}$ depth of the GAC bed as expected due to the catalytic action of the activated carbon (AWWA, 1990). The temperature of the influent water varied seasonally, whith an average value of $13^{\circ} \mathrm{C}$ during the filter-adsorber operation and $15^{\circ} \mathrm{C}$ during the postfilter-adsorber operation. The mean $\mathrm{pH}$ of water was 7.5 and the mean bromide concentration was $23.4 \mathrm{\mu g} \mathrm{L}^{-1}$ for the filter-adsorber and $3.6 \mathrm{\mu g} \mathrm{L}^{-1}$ for the postfilter-adsorber.

\subsection{THMs removal profiles and calculations}

THMs are small volatile molecules, which are hydrophobic and non biodegradable. They are adsorbed on GAC to some extent (AWWA, 1990; Arora et al., 1997; Speth and Miltner, 1990; 1998). The breakthrough point for individual THMs was defined as the point of $0 \%$ removal, which was not significantly and continuously exceeded during the further operation of the GAC adsorber. The measured influent and effluent concentrations of the individual THMs have been plotted versus the volume of treated water (removal profiles: Figures 1-6). The analytical error in the detection of concentrations of THMs (Nikolaou et al., 2002a) was taken into account in the assessment of the results.

From the THMs removal profiles (Figures 1-6): For the GAC filter-adsorber, breakthrough for TCM and BDCM occurred between the $8^{\text {th }}$ and $9^{\text {th }}$ sampling event, while for DBCM it occurred after the $10^{\text {th }}$ sampling event. For the GAC postfilter-adsorber, breakthrough for TCM and BDCM occurred between the $4^{\text {th }}$ and $5^{\text {th }}$ sampling event, while for DBCM it occurred between the $7^{\text {th }}$ and $8^{\text {th }}$ sampling event.

Some desorption incidents of TCM and BDCM were noticed during the operation of both GAC adsorbers, after a sudden drop in influent concentration or near the breakthrough point (Figures 1-4). These incidents are expected for weakly adsorbing compounds and are usually caused by either 
sudden decreases in influent concentration or the presence of stronger adsorbing compounds (Thacker et al, 1983; Voudrias et al., 1986; AWWA,1990).

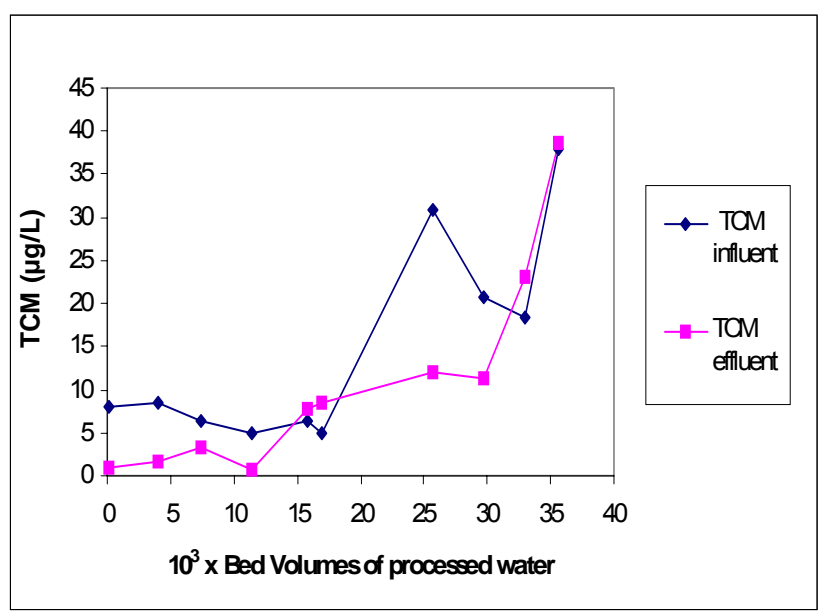

Figure 1. TCM removal profile by GAC filter-adsorber EBCT: $9.5 \mathrm{~min}$, flow rate: $7.2 \mathrm{~m} \mathrm{~h}^{-1}$, bed depth: $1.14 \mathrm{~m}$

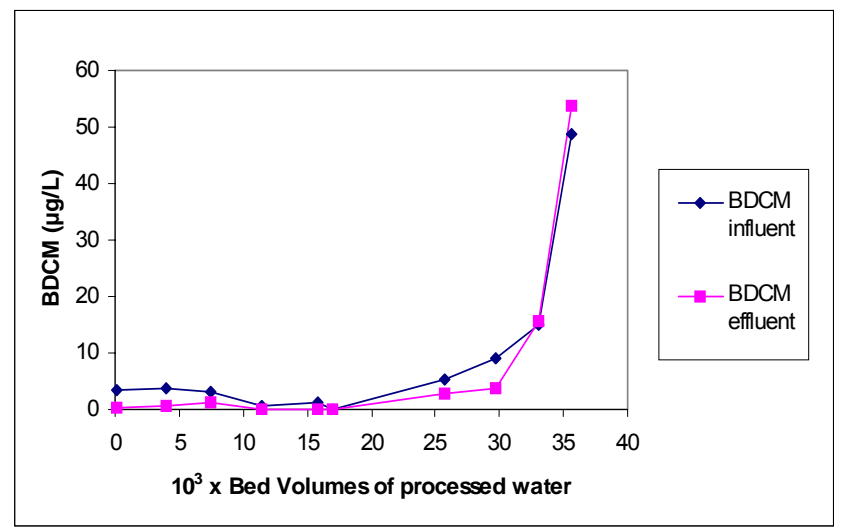

Figure 3. BDCM removal profile by GAC filter-adsorber EBCT: $9.5 \mathrm{~min}$, flow rate: $7.2 \mathrm{~m} \mathrm{~h}^{-1}$, bed depth: $1.14 \mathrm{~m}$

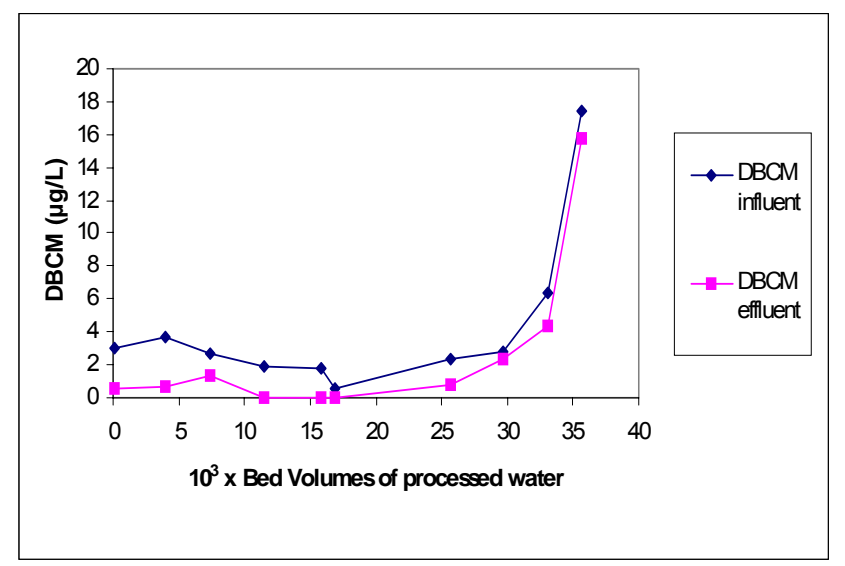

Figure 5. DBCM removal profile by GAC filter-adsorber EBCT: $9.5 \mathrm{~min}$, flow rate: $7.2 \mathrm{~m} \mathrm{~h}^{-1}$, bed depth: $1.14 \mathrm{~m}$

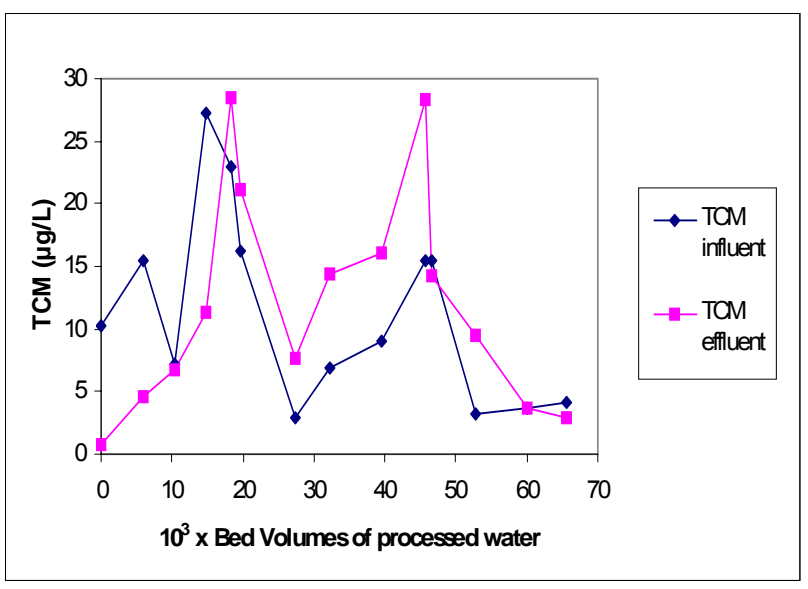

Figure 2. TCM removal profile by GAC postfilter-adsorber

EBCT: $14 \mathrm{~min}$, flow rate: $4.8 \mathrm{~m} \mathrm{~h}^{-1}$, bed depth: $1.13 \mathrm{~m}$

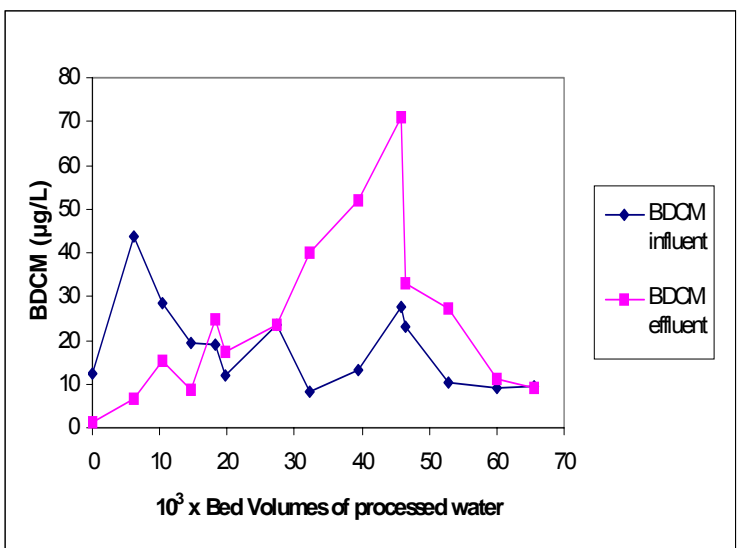

Figure 4. BDCM removal profile by GAC postfilter-adsorber

EBCT: $14 \mathrm{~min}$,flow rate: $4.8 \mathrm{~m} \mathrm{~h}^{-1}$,bed depth: $1.13 \mathrm{~m}$

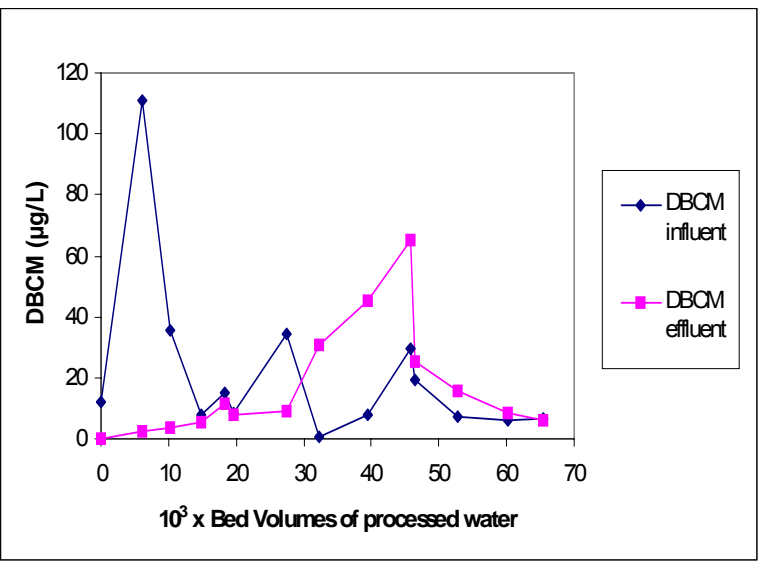

Figure 6. DBCM removal profile by GAC postfilter-adsorber

EBCT: $14 \mathrm{~min}$, flow rate: $4.8 \mathrm{~m} \mathrm{~h}^{-1}$, bed depth: $1.13 \mathrm{~m}$ 
The cumulative influent and effluent mass of the specific compounds at each sampling point was calculated from the area between the respective curves and the axis of water volume in Figures 1-6. This was based on the assumption that between two successive sampling events the influent and effluent concentrations were constant and equal to the arithmentic mean of the respective values of the two sampling events. The cumulative mass removal of the compounds by GAC was calculated by subtracting the cumulative influent and effluent mass during the filter-adsorber operation.

The final results at breakthrough, including GAC bed life (Bed Volumes of water), GAC loading (total adsorbed mass of a specific compound per unit mass of carbon), carbon usage rate ( $\mathrm{g}$ of GAC per $\mathrm{m}^{3}$ of treated water, CUR) and time of operation were calculated by linear interpolation. All the above results are presented in Table 2.

Table 2: Final results for THMs at breakthrough (0\% removal) for both GAC adsorbers

\begin{tabular}{lccccccc}
\hline & \multirow{2}{*}{ units } & \multicolumn{2}{c}{ GAC filter-adsorber (A) } & \multicolumn{2}{c}{ GAC postfilter-adsorber(B) } \\
\cline { 2 - 7 } & & TCM & BDCM & DBCM* & TCM & BDCM & DBCM \\
\hline $\begin{array}{l}\text { Average } \\
\text { infl.con. }\end{array}$ & $\mu \mathrm{L} \mathrm{L}^{-1}$ & 13.25 & 3.61 & 3.14 & 15.49 & 27.88 & 35.80 \\
\hline $\begin{array}{l}\text { GAC } \\
\text { loading }\end{array}$ & $\mathrm{mg} \mathrm{kg}^{-1} \mathrm{GAC}$ & 458.0 & 149.4 & 130.4 & 334.1 & 751.9 & 2061.0 \\
\hline $\begin{array}{l}\text { Time to } \\
\text { BT }\end{array}$ & Days & 210.5 & 215.2 & 235 & 169 & 165.5 & 288 \\
\hline $\begin{array}{l}\text { GAC } \\
\text { bed life }\end{array}$ & $\begin{array}{c}\text { bed } \\
\text { volumes }\end{array}$ & 31917 & 32626 & 35632 & 17351 & 16987 & 29570 \\
\hline CUR & $\begin{array}{l}\text { g GAC } \\
m^{-3} \text { water }\end{array}$ & 13.47 & 13.18 & 12.07 & 25.49 & 25.02 & 14.37 \\
\hline
\end{tabular}

${ }^{*}$ For DBCM, at the end of experimental cycle with the filter-adsorber and before breakthrough

The interpretation of the results was made under the hypothesis that at breakthrough, as it was defined, equilibrium had been established between the concentration of the adsorbed compounds on the whole GAC bed and their average concentration in the influent water. The equilibrium is described by the Freundlich isotherm (Treybal, 1980).

The average influent concentration of each compound of interest until breakthrough (Table 2) was calculated by dividing the cumulative influent mass of the compound until breakthrough by the total volume of treated water. It was considered to represent the real mean concentration in contact with the GAC better than does the simple average of the measured influent concentrations. As is seen in Table 2, the average influent concentration of THMs members was different from one another. TBM was almost not detected in influent water.

By correlating the mean influent concentration of TCM, BDCM and DBCM and the concentration of their adsorbed mass on GAC bed at equilibrium, by linear regression, to conform to the Freundlich isotherm, the Freundlich constants $1 / \mathrm{n}$ and $\mathrm{k}$ were calculated (Table 3 ), with the hypothesis that the temperature of water was constant and equal to the average water temperature during both adsorption cycles $\left(14{ }^{\circ} \mathrm{C}\right)$. The values of $1 / \mathrm{n}$ and $\mathrm{k}$ for each THM species are apparent values for natural water and are related to its physicochemical characteristics and its present composition, as well as to the specific GAC used.

From Table 3, we can see that the constant $1 / \mathrm{n}$ is lower for the THM species with higher number of bromine atoms for both GAC adsorbers, fact which, according to the classical adsorption theory, is probably indicative of the stronger adsorption bond between the more brominated species and GAC. This fact confirms conclusions by other researchers (Speth and Miltner, 1990; AWWA, 1990).

Comparison of the $1 / n$ values of individual THMs for $\mathrm{GAC}(\mathrm{B})$ and $\mathrm{GAC}(\mathrm{A})$ could give some indication of the relative strength of the adsorption bond. The $1 / n$ values for $G A C(B)$ are generally lower or close and not very different from the respective ones for $G A C(A)$. This fact indicates that the adsorption bond of THMs with $\mathrm{GAC}(\mathrm{B})$ is probably stronger than with $\mathrm{GAC}(\mathrm{A})$. This is probably due to GAC surface chemistry and the background matrix in water. 
Table 3. Freundlich constants $1 / \mathrm{n}$ kaı $\mathrm{k}$ of TCM, BDCM and DBCM for GAC adsorbers

\begin{tabular}{|c|c|c|c|c|c|c|c|}
\hline THMs & $1 / n$ & $\mathbf{n}$ & $\log k$ & $\begin{array}{c}\mathrm{K} \\
\left(\mu g g^{-1}\right) \cdot\left(L \mu g^{-1}\right)^{(1 / n)}\end{array}$ & $\mathrm{N}^{*}$ & $\mathbf{R}^{2}$ & $\begin{array}{c}\text { Range of mean } \\
C_{\text {infl }}\left(\mu \mathrm{L} \mathrm{L}^{-1}\right)\end{array}$ \\
\hline & \multicolumn{7}{|c|}{ GAC filter-adsorber (A) } \\
\hline TCM & 1.798 & 0.556 & 0.722 & 5.266 & 4 & 0.916 & $10.5-14.3$ \\
\hline BDCM & 0.894 & 1.118 & 1.661 & 45.804 & 3 & 0.925 & $2.4-3.9$ \\
\hline \multirow[t]{2}{*}{ DBCM } & 0.460 & 2.173 & 1.889 & 77.500 & 3 & 0.956 & $2.2-3.1$ \\
\hline & \multicolumn{7}{|c|}{ GAC postfilter-adsorber(B) } \\
\hline TCM & 1.533 & 0.652 & 0.666 & 4.638 & 4 & 0.862 & $12.2-16.2$ \\
\hline BDCM & 0.680 & 1.472 & 1.895 & 78.451 & 3 & 0.998 & $24.0-27.2$ \\
\hline DBCM & 0.560 & 1.670 & 2.323 & 210.378 & 4 & 0.376 & $28.3-42.5$ \\
\hline
\end{tabular}

${ }^{*} \mathrm{~N}$ : number of points

Furthermore, the Freundlich constant $k$, which is related to the GAC capacity was higher for DBCM, lower for BDCM and even lower for TCM for each adsorber. This result agrees with those by other researchers, according to which the higher the number of bromine atoms THMs molecules contain, the better they are adsorbed on carbon (Speth and Miltner 1990; AWWA, 1990; Clark et al., 1991).

In addition, the constant $k$ values of $B D C M$ and $D B C M$ are higher for $G A C(B)$, than those for $\operatorname{GAC}(A)$. This result indicates that GAC(B) capacity for these species is higher than that of $G A C(A)$. This is probably due to the larger surface area and the surface chemistry of GAC(B) (AWWA, 1990). Other factors may have also increased GAC postfilter-adsorber capacity: The lower mean grain size has probably resulted in increased rate of adsorption, its higher uniformity coefficient has given better GAC stratification after backwashing and has prevented premature desorption and breakthrough, and the applied lower flow rate has allowed more time to GAC particles to reach equilibrium (AWWA, 1990). In case of TCM, though, the k value was lower for the GAC postfilteradsorber, under the present experimental conditions.

According to the classical theory of adsorption, competitive adsorption by other species can influence the adsorption of compounds. The extent of competition on GAC depends upon the strength of adsorption and the concentration of the competing molecules and also the type of GAC (AWWA, 1990). For the interpretation of the above results at equilibrium between adsorbed and dissolved THMs (Table 3), the average concentration of each THM species and natural organic matter (DOC) is also important (Table 4).

Table 4. Mean influent concentrations of THMs and DOC at breakthrough

\begin{tabular}{|c|c|c|c|c|c|c|c|c|}
\hline \multirow{4}{*}{$\begin{array}{l}\text { THMs } \\
\text { breakthrough }\end{array}$} & \multirow{2}{*}{\multicolumn{4}{|c|}{$\begin{array}{c}\text { GAC filter-adsorber }(A) \\
\text { Mean influent concentration }\end{array}$}} & \multirow{2}{*}{\multicolumn{4}{|c|}{$\begin{array}{l}\text { GAC postfilter-adsorber (B) } \\
\text { Mean influent concentration }\end{array}$}} \\
\hline & & & & & & & & \\
\hline & $\left(\mu \mathrm{g} \mathrm{L}^{-1}\right)$ & $\left(\mu \mathrm{g} \mathrm{L}^{-1}\right)$ & $\left(\mu \mathrm{g} \mathrm{L}^{-1}\right)$ & $\left(\mathrm{mg} \mathrm{L}^{-1}\right)$ & $\left(\mu \mathrm{g} \mathrm{L}^{-1}\right)$ & $\left(\mu \mathrm{g} \mathrm{L}^{-1}\right)$ & $\left(\mu \mathrm{g} \mathrm{L}^{-1}\right)$ & $\left(\mathrm{mg} \mathrm{L}^{-1}\right)$ \\
\hline & TCM & BDCM & DBCM & DOC & TCM & BDCM & DBCM & DOC \\
\hline TCM & 13.3 & 3.9 & 2.5 & 1.71 & 15.5 & 27.2 & 45.0 & 3.98 \\
\hline BDCM & 13.3 & 3.6 & 2.5 & 1.71 & 15.9 & 27.9 & 45.0 & 3.98 \\
\hline \multirow[t]{3}{*}{ DBCM } & 14.3 & 5.9 & 3.1 & 1.81 & 12.9 & 22.8 & 35.8 & 3.04 \\
\hline & \multicolumn{3}{|c|}{$\begin{array}{l}\text { Percentage of individual } \\
\text { THMs concentration }(\%)\end{array}$} & $\begin{array}{l}\text { C }_{\text {infl }} \text { ratio } \\
\left(\mu \mathrm{mg}^{-1}\right)\end{array}$ & \multicolumn{3}{|c|}{$\begin{array}{l}\text { Percentage of individual } \\
\text { THMs concentration (\%) }\end{array}$} & $\begin{array}{l}C_{\text {inf }} \text { ratio } \\
\left(\mu \mathrm{mg}^{-1}\right)\end{array}$ \\
\hline & $\mathrm{TCM}$ & BDCM & DBCM & TTHMs/DOC & TCM & BDCM & DBCM & TTHMs/DOC \\
\hline TCM & 67.5 & 19.8 & 12.7 & 11.5 & 17.7 & 31.0 & 51.3 & 22.0 \\
\hline BDCM & 68.6 & 18.6 & 12.9 & 11.4 & 17.9 & 31.4 & 50.7 & 22.3 \\
\hline DBCM & 61.4 & 25.3 & 13.3 & 12.9 & 18.0 & 31.9 & 50.1 & 23.5 \\
\hline
\end{tabular}

In Table 4, it is seen that TCM had almost the same mean influent concentration in both adsorbers, but was in higher mean concentration in the filter-adsorber influent water than the other two THM species, while it was in much lower concentration than both of them in the postfilter-adsorber influent water. This fact could justify a stronger competition effect on TCM adsorption by the stronger 
adsorbing and more concentrated BDCM and DBCM during the postfilter-adsorber operation, on condition that the three THM species of similar structure are competing for the same adsorption sites (AWWA, 1990).

Because of the differences among $1 / \mathrm{n}$ values and equilibrium (mean influent) concentrations of individual THMs (Tables 3, 4), in both GAC adsorbers, the comparison of the GAC capacity for each of them should be based on the GAC equilibrium loading, with the hypothesis of equal THMs mean influent concentrations. We supposed that the Freundlich isotherm can be used with the same constants of TCM, BDCM and DBCM for $\mathrm{GAC}(\mathrm{B})$, if the equilibrium concentrations are lower than the experimental ones. The selected common mean influent concentrations of THM species are within the range of the experimental ones for the filter-adsorber (lower than those for the postfilteradsorber).

The results are presented in Table 5.

Table 5. GAC equilibrium loading of THMs for equal mean influent concentrations

\begin{tabular}{lccccccccc}
\hline & \multicolumn{4}{c}{ GAC filter-adsorber } & \multicolumn{3}{c}{ GAC postfilter-adsorber } \\
\hline & units & TCM & TCM & BDCM & DBCM & TCM & TCM & BDCM & DBCM \\
\hline $\begin{array}{l}\text { Average } \\
\text { infl.conc. }\end{array}$ & $\mathrm{mg} \mathrm{L}^{-1}$ & 12.0 & 3.0 & 3.0 & 3.0 & 12.0 & 3.0 & 3.0 & 3.0 \\
$\begin{array}{l}\text { GAC } \\
\text { loading }\end{array}$ & $\begin{array}{c}\mathrm{mg} \mathrm{kg}^{-1} \\
\text { GAC }\end{array}$ & 459.5 & 37.8 & 122.3 & 128.5 & 209.2 & 25.0 & 165.5 & 406.2 \\
\hline
\end{tabular}

From Table 5, it is seen that in both GAC adsorbers DBCM is better adsorbed than BDCM, and BDCM is much better adsorbed than TCM, in case of equal influent concentrations $(3 \mu \mathrm{g} / \mathrm{L})$.

These results confirm, as expected, the conclusion by other researchers that the higher the number of bromine atoms THMs molecules contain, the better they are adsorbed on carbon (Speth and Miltner 1990; AWWA, 1990; Clark et al., 1991).

In addition, BDCM and DBCM are better adsorbed by the GAC postfilter-adsorber, while TCM is better adsorbed by the GAC filter-adsorber. Since the GAC characteristics and operational parameters of the postfilter-adsorber are more favourable to adsorption, the TCM exception is attributed to the competition effect by BDCM and DBCM, as was mentioned before.

The DOC content of GAC influent water must have also had a significant effect on the adsorption of the three THM species, since it was rather high (Table 4). To assess that, the Freundlich constants $1 / n$ and $k$ found in our experiments with the GAC postfilter-adsorber and natural water $\left(\right.$ at $\left.14{ }^{\circ} \mathrm{C}\right)$, were compared with the respective ones by Speth and Miltner (1990) isotherm experiments, with the same type of carbon (F-400) and distilled-deionized water (at $24{ }^{\circ} \mathrm{C}$ ). This comparison is possible since the range of THMs concentrations in our experiments is within the respective ranges used by the above researchers and on condition that the temperature difference does not have significantly influenced the results.

From the above comparison, it came out that the Freundlich constants $1 / \mathrm{n}$ of BDCM and DBCM for GAC(B) are almost the same (3.6 and $12 \%$ difference, respectively) as those by Speth and Miltner, while that of TCM is $56 \%$ higher than the respective by the above researchers. This fact implies that the adsorption bond of BDCM and DBCM with $\mathrm{GAC}(\mathrm{B})$ has not been significantly affected by the presence of other organics in water, while that of TCM has been affected.

In addition, the Freundlich constants $\mathrm{k}$ for TCM, BDCM and DBCM (related to GAC capacity), which were found in our experiments with the postfilter-adsorber were generally lower than the respective ones for distilled-deionized water. Reduction of the GAC adsorption capacity for specific compounds due to the presence of background organics has also been referred by other researchers (AWWA, 1990). Possibly, a significant part of the GAC surface is occupied by the adsorbed organics, and so the GAC capacity for THMs is reduced. The Freundlich constant k of TCM in our natural water was at least 12 times lower than in distilled-deionized water, while those for BDCM and DBCM it were only 2 and 2.5 times lower, respectively. The higher reduction in GAC capacity for the weak adsorbing TCM may be attributed additionally to the stronger competition effect on TCM adsorption by the stronger adsorbing BDCM and DBCM (mentioned again before), both being in much higher influent concentration in our water. 


\section{CONCLUSIONS}

This work has evaluated the adsorption capacity for individual THMs of a GAC filter-adsorber and a GAC postfilter-adsorber, both fed with chlorinated natural water.

From the experimental results, GAC bed life, GAC usage rate, GAC loading and operation time to breakthrough were calculated for most THMs. TBM was almost not detected. In addition, some desorption of THMs, especially TCM and BDCM, was noticed during the operation of both GAC adsorbers, probably caused by a sudden drop of influent concentration or competitive adsorption.

Near the breakthrough point for each of THMs, equilibrium between adsorbed THMs on GAC bed and dissolved THMs in influent water has been considered to be reached. The GAC loading at equilibrium was assumed to depend on the average influent concentration of individual THMs, since their instant influent concentration was not constant during operation.

By correlating the equilibrium data by linear regression to conform to the Freundlich isotherm, the Freundlich constants $1 / \mathrm{n}$ and $\mathrm{k}$ were determined for each of THMs. They are related to the physicochemical characteristics and background organics of water and the specific GAC used. The strength of the adsorption bond and the GAC capacity was higher for DBCM, lower for BDCM and even lower for TCM for each adsorber. The above results support the conclusion by other researchers that the higher the number of bromine atoms THMs molecules contain, the better they are adsorbed on carbon.

In addition, the $\mathrm{GAC}(\mathrm{B})$ capacity for $\mathrm{BDCM}$ and $\mathrm{DBCM}$ was higher than that of $\mathrm{GAC}(\mathrm{A})$, probably due to the larger surface area and the surface chemistry of GAC(B). GAC lower particle size, higher uniformity coefficient and lower flow rate to the postfilter-adsorber may also have attributed to that by enhancing GAC particles equilibration. However, TCM was less adsorbed by the postfilter-adsorber, probably due to the stronger competition effect by the stronger adsorbing BDCM and DBCM, being in much higher mean concentration in its feed water.

The DOC content of influent water seems also to reduce significantly the adsorption of THMs, (especially TCM), as the comparison of our results with the isotherm results with distilled-deionized water by other researchers showed.

The above findings represent real operation conditions for Athens drinking water.

Further research is recommended on competitive adsorption effect on the adsorption of THMs to GAC.

\section{ACKNOWLEDGEMENTS}

The authors gratefully acknowledge the Athens Water Supply and Sewerage Company (EYDAP), for supporting this work.

\section{REFERENCES}

1. American Water Works Association (1990), Water Quality and Treatment, A Handbook of Community Water Supplies, $4^{\text {th }}$ edition, Mc Graw Hill, U.S.A.

2. APHA (1992), Standard Methods For the Examination of Water and Wastewater, $18^{\text {th }}$ ed., American Public Health Association, Washington.

3. Arora, H., LeChevalier, M.W., and Dixon, K.L. (1997), DBP occurence survey, J.AWWA, 89(6), 60 68.

4. Babi, K.G., Koumenides, K.M., Nikolaou, A.D., Makri, C.A. Tzoumerkas, F.K., and Lekkas, T. D., (2007), Pilot study of the removal of THMs, HAAs and DOC from drinking water by GAC adsorption, Desalination, 210, 215-224.

5. Babi, K.G., Koumenides, K.M., Nikolaou, A.D., Mihopoulos, N.S., Tzoumerkas, F.K., Makri, C.A. and Lekkas, T. D., (2003), Pilot-plant experiments for the removal of THMs, HAAs and DOC from drinking water by GAC adsorption- Galatsi Water Treatment Plant, Athens, Global Nest:The Int. J., 5 (3), 177184.

6. Black, B. D., Harrington, G. W., and Singer, P.C., (1996), Reducing cancer risks by improving organic carbon removal, J.AWWA, 88(6), 40-52.

7. Clark, R. M., and Lykins, B.W., Jr., Granular Activated Carbon, Design, Operation and Cost, $2^{\text {nd }}$ ed., Lewis Publishers, Michigan, U.S.A., 1991.

8. Clark, R.M., Adams, J.Q., and Lykins, B.W.Jr.,(1994), DBP control in drinking water: cost and performance, Journal of Environmental Engineering, 120 (4), 759-782.

9. Clark, R.M. and Boutin, B.K.,ed.,(2001), Controlling Disinfection by-Products and Microbial Contaminants in Drinking Water, EPA/600/R-01/110, Environmental Protection Agency, Cincinnati, $\mathrm{OH}$.

10. EEC, Council Directive 98/83/EC of 3 November 1998 on the quality of water intended for human 
consumption, Official Journal of the European Communities, L 330/32, 5.12.98 (1998).

11. Chowdhury, S. and Champagne, P., (2008), An investigation on parameters for modeling THMs formation, Global NEST J., 10 (1), 80-91.

12. Golfinopoulos S.K., Nikolaou A.D. and Lekkas T.D., (2003), The occurrence of disinfection byproducts in the drinking water of Athens, Greece, J. Environmental Science and Pollution Research, 10(6), 368-372.

13. Golfinopoulos, S. K. and Nikolaou, A.D. (2005), Formation of DBPs in the drinking water of Athens, Greece: a ten year study, Global NEST J., 7(1), 106-118.

14. Graese, S. L., Snoeyink, V. L., and Lee, R. G.,(1987), Granular activated carbon filter- adsorber systems, J. AWWA, 79 (12), $64-73$.

15. Nieuwenhuijsen, M.J.(2005), Adverse reproductive health effects of exposure to chlorination disinfection by products, Global NEST J., 7(1), 128-144.

16. Nikolaou, A. D., Lekkas, T. D., Golfinopoulos, S. A., and Kostopoulou, M. N., (2002a), Application of different analytical methods for determination of volatile chlorination by-products in drinking water, Talanta 56 (4), 717-726.

17. Nikolaou A.D., Golfinopoulos S.K., Lekkas T.D., Kostopoulou M.N.,(2004), DBP levels in chlorinated drinking water: effect of humic substances, J. Environmental Monitoring and Assessment, 93, 301319.

18. Richardson, S.D. (2005), New disinfection by-product issues: emerging DBPs and alternative routes of exposure, Global NEST J., 7 (1), 43-60.

19. Singer, P. C., (1994), Control of disinfection by-products in drinking water, Journal of Environmental Engineering, 120 (4), 727-744.

20. Speth, T.F.and Miltner, R.J., (1990), Technical note: Adsorption capacity of GAC for synthetic organics, J.AWWA, 82(2), 72-75

21. Speth, T.F.and Miltner, R.J., (1998), Technical note: Adsorption capacity of GAC for synthetic organics, J.AWWA, 90 (4), 171-174.

22. Thacker, W.E., Snoeyink, V.L. and Crittenden, J.C., (1983), Desorption of compounds during operation of GAC adsorption systems, J.AWWA, 75 (3), 144-149.

23. Treybal, R.E.,(1980), Mass-Transfer Operations, McGraw-Hill Book Company, $3^{\text {rd }}$ ed., New York.

24. USEPA (1998), National Primary Drinking Water Regulations: Disinfectants and Disinfection ByProducts Notice of Data Availability, Office of Ground Water and Drinking Water, http:/www.epa.gov/OGWDW/mdbp/dis.html.

25. USEPA (1998a), EPA Method 551.1, USEPA, National Exposure Research Laboratory, Office of Research and Development, Cincinnati, OH 45268.

26. USEPA (2001), Controlling Disinflection By-Products and Microbial Contaminants in Drinking Water, Office of Research and Development, Washington DC 20460, EPA/600/R-01/110, December 2001.

27. Voudrias, E.A., Snoeyink.V.L. and Larson, R.A., (1986), Desorption of Organics Formed on Activated Carbon, J.AWWA, 78 (2), 82-86.

28. WHO (2004), Guidelines for drinking water quality, $3^{\text {rd }}$ ed., Vol. 1, Chapter 12, pp. 316-454.

29. Xie, YFF, and Zhou, HJ, (2002), Use of BAC for HAA removal- Part 2, column study, J.AWWA, 94(5), 126-134.

30. Zhou, H.J., and Xie,Y.F.,(2002), Using BAC for HAA removal - Part 1: Batch study, J.AWWA, 94(4), 194-200. 